\title{
Research
}

Renée M Wildeboer, Lucas van der Hoek and Peter FM Verhaak

\section{Use of general practice services 5 years after an episode of mental illness:}

\author{
case-control study using electronic records
}

\begin{abstract}
Background

Depression, anxiety, and emotional distress occur frequently and are usually treated in general practice. Little has been reported about the long-term course of these conditions and the long-term use of medical services.

\section{Aim}

To follow up patients with depression, anxiety, and emotional distress in general practice for 5 years and examine the length and number of index episodes, prescribing behaviour, and the use of services in general practice.
\end{abstract}

\section{Design and setting}

A case-control study using data from electronic medical records.

\section{Method}

Three cohorts of patients with depression ( $n=453)$, anxiety ( $n=442)$, and emotional distress ( $n=185$ ) were compared against a cohort of control patients $(n=4156)$ during a 5-year follow-up from 2007 to 2011. The occurrence or recurrence of the index disorders, other psychological disorders or medical conditions, the numbers of prescriptions, and the number of contacts with the general practice were all examined.

\section{Results}

Patients in the depression group had 1.1 followup episodes of depression, those in the anxiety group had 0.9 follow-up episodes of anxiety, and those in the emotional distress group had 0.5 follow-up episodes of emotional distress during the 5 years. All three groups had more consultations (for both psychological and somatic reasons) during each of the follow-up years than control patients. Furthermore, the groups with mental health disorders were given more prescriptions for psychopharmacological treatment.

\section{Conclusion}

Five years after the index episode in 2007, patients with an episode of depression, anxiety, or emotional distress are still not comparable with control patients, in terms of the prevalence of mental health conditions, the number of prescriptions, and healthcare use.

\section{Keywords}

anxiety disorders; depressive disorder; emotional distress; follow-up; general practice; mental health.

\section{INTRODUCTION}

Depression and anxiety are among the most prevalent mental health conditions in the population, ${ }^{1}$ and if they are treated at all it is mostly in general practice. ${ }^{2,3}$

From cross-sectional studies, ${ }^{4-10}$ it is known that not all mental health conditions are recognised in general practice, partly because psychiatric and somatic comorbidity are common. ${ }^{11-15}$ As a result of this comorbidity, patients with depression or anxiety are intensive users of medical care. ${ }^{11,15}$

The long-term prognosis of depression and anxiety is generally poor, with a substantial proportion of patients not recovering and with many recurrences; the initial severity is an important predictor. ${ }^{16-23}$ Regarding the long-term presentation of depression in general practice, it has been reported that about $40 \%$ of patients have a recurrence of depression in general practice within a 10-year period. ${ }^{24,25}$ Lloyd et $a^{26}$ found relapses or chronic psychiatric conditions after 11 years in one-third of those included with neurotic disorders.

Recent studies have analysed healthcare use, ${ }^{27,28}$ but most of these studies use data derived from samples of the general population, not from general practice. Furthermore, these studies are cross-sectional. For the use of general practice services, only Lloyd et al ${ }^{26}$ provide longitudinal data but they consider a global category of 'neurotic illness' and do not

RM Wildeboer, MSc, MD, GP, Department of General Practice, University Medical Center Groningen, Groningen, the Netherlands. L van der Hoek, MSc, statistician, the Netherlands Institute of Health Services Research (NIVEL), Utrecht, the Netherlands. PFM Verhaak, PhD, professor Department of General Practice, University Medical Center Groningen, Groningen; NIVEL, Utrecht, the Netherlands.

\section{Address for correspondence}

Peter FM Verhaak, NIVEL, postbox 1568, 3500 BN specify the GP's original diagnosis.

Therefore, this study proposes a more elaborate approach and includes patients with an episode of depression, anxiety, or emotional distress las diagnosed by the GPJ. It followed these patients for 5 years, together with a control group with comparable age-sex distribution. The aim of the study was to describe the course of these episodes during a 5-year follow-up and the use of general practice services during this follow-up period.

\section{METHOD}

\section{Population and case definition}

Data were obtained from the NIVEL Primary Care Database, a Dutch database containing routinely kept electronic medical record data, equally distributed throughout the Netherlands. All contacts with the GP are recorded in this database with information about diagnosis and prescription, with the exception of managed care data (such as for diabetes care) in some electronic medical records for 2009

For the period 2007-2011, it was possible to obtain continuous data covering the full 5 years with reliable figures on morbidity and prescription from 15 practices. Patients with a new episode of depression ( $n=453)$, anxiety $(n=442)$, or emotional distress ( $n=185)$ between 1 April 2007 and 31 December 2007 were included in the study and followed up until 2012. If more than one of the index episodes were applicable,
Utrecht, the Netherlands.

E-mail: p.verhaakanivel.nl

Submitted: 21 August 2015; Editor's response: 8 September 2015; final acceptance: 25 October 2015. @British Journal of General Practice This is the full-length article (published online 15 Apr 2016) of an abridged version published in print. Cite this article as: Br J Gen Pract 2016; DOI: 10.3399/bjgp16X684973 


\section{How this fits in}

Depression, anxiety, and emotional distress are the most prevalent mental health conditions in general practice. A great deal of (cross-sectional) research has been published about the recognition and treatment of these conditions. However, the presentation of symptoms of depression, anxiety, or emotional distress in the longer term in general practice and the resulting use of healthcare services have received less attention.

patients were included in the 'depression group if applicable, then in 'anxiety', and then in 'emotional distress'.

These cohorts were compared against 4156 control patients from the same practices with a comparable age-sex distribution and without any episodes of mental illness in 2007. All patients were aged 18-91 years in 2007.

\section{Length of each episode}

The index episode started on the day the diagnosis was recorded by the GP for the first time. A recurrent episode was defined as a new episode after a minimum of 3 months without any contacts or prescription concerning the index episode. This 3-month criterion was in line with other studies. ${ }^{18,24}$ The database contains two dates for each episode: the first and last contacts. Subtraction gives the number of days an episode lasts.

\section{Contacts and prescriptions}

The GPs in the NIVEL Primary Care Database record all contacts in their electronic medical records. They label all health problems using International Classification of Primary Care (ICPC) codes. ${ }^{29}$ The ICPC codes were clustered into:

- depression (P03, P76);

- anxiety (P01, P74);

- emotional distress (P02, P78);

- other psychological problems lall other classifications in ICPC chapter ' $P$ '); and

- non-psychological diagnosis lall other classifications in other ICPC chapters).

GPs should only use codes for disorders $(P 74, P 76)$ if the episode meets the criteria for a major depressive disorder or anxiety disorder as defined by DSM-IV. In the case of symptoms of anxiety or depression, GPs should restrict the symptom codes to P01 and P03.

All recorded consultations, except for requests for repeat prescriptions, were included in order to calculate the number of contacts. As GPs differ in their preference for coding symptoms or disorders, disorders and symptoms were recorded so that all data were captured.

\section{Table 1. Characteristics of the three patient groups and the control group in 2007}

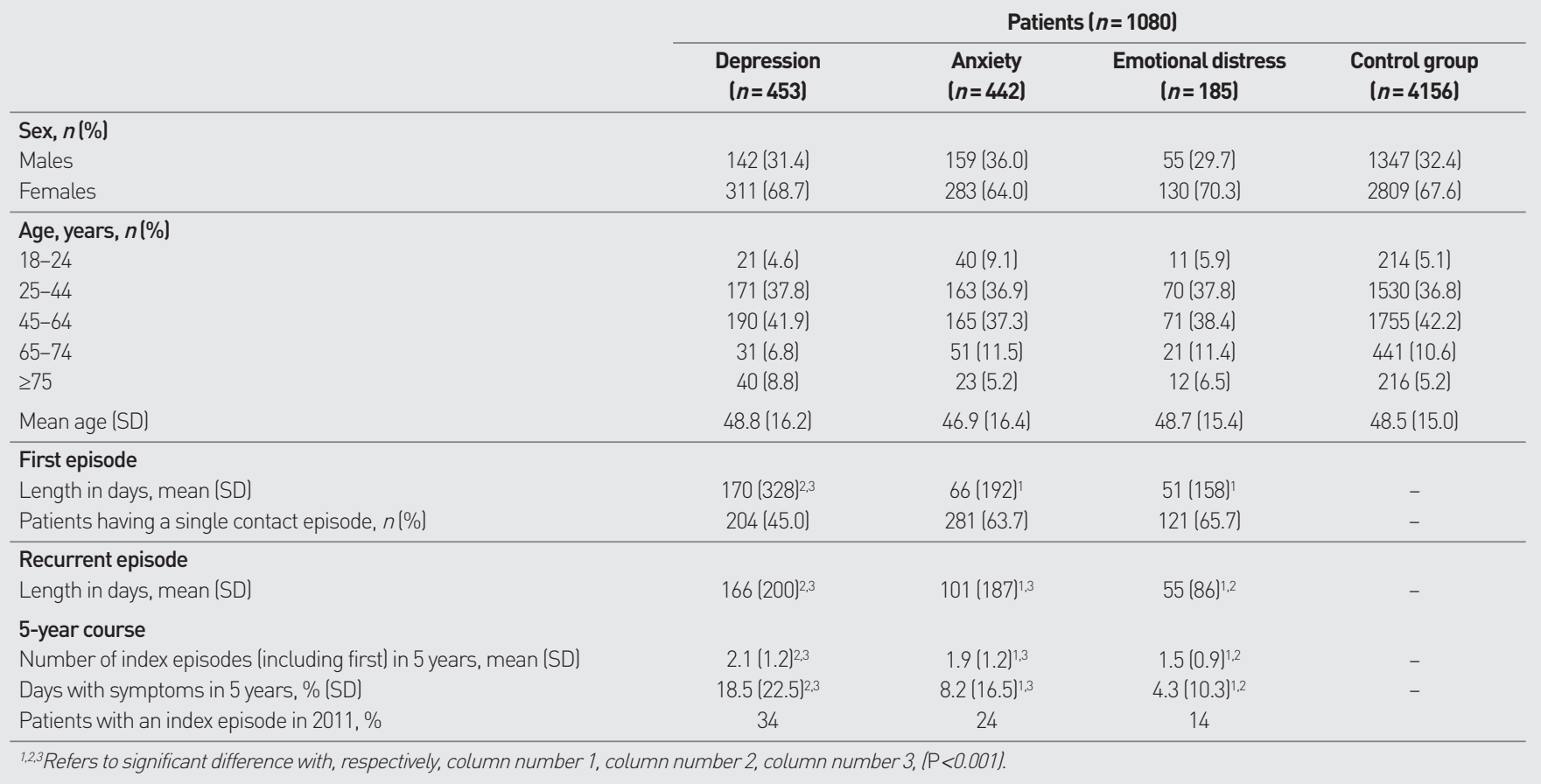


Table 2. Mean number of episode days, corrected for age, sex, and practice

\begin{tabular}{|c|c|c|c|c|}
\hline Variable & Coefficient & SE & $P$-value & $95 \% \mathrm{Cl}$ \\
\hline Age & 0.20 & 0.13 & 0.12 & -0.05 to -0.46 \\
\hline Sex & 5.69 & 4.34 & 0.19 & -2.82 to 14.21 \\
\hline \multicolumn{5}{|l|}{ Patient group } \\
\hline Depression (ref) & - & & & \\
\hline Anxiety & -102.87 & 9.66 & 0.000 & -121.80 to -83.94 \\
\hline Emotional distress & -122.73 & 12.69 & 0.000 & -147.60 to -97.87 \\
\hline \multicolumn{5}{|l|}{ Year } \\
\hline 2007 (ref) & - & & & \\
\hline 2008 & -128.01 & 9.47 & 0.000 & -146.56 to -109.46 \\
\hline 2009 & -136.89 & 9.47 & 0.000 & -155.45 to -118.34 \\
\hline 2010 & -126.34 & 9.47 & 0.000 & -144.89 to -107.78 \\
\hline 2011 & -130.39 & 9.47 & 0.000 & -148.94 to -111.83 \\
\hline \multicolumn{5}{|l|}{ Group $\times$ year } \\
\hline$A n x \times 2008$ & 87.63 & 13.47 & 0.000 & 61.23 to 114.03 \\
\hline Anx $\times 2009$ & 83.08 & 13.47 & 0.000 & 56.68 to 109.48 \\
\hline Anx $\times 2010$ & 77.27 & 13.47 & 0.000 & 50.87 to 103.68 \\
\hline Anx $\times 2011$ & 92.63 & 13.47 & 0.000 & 66.23 to 119.04 \\
\hline Emo $\times 2008$ & 83.4 & 17.58 & 0.000 & 48.95 to 117.86 \\
\hline Emo $\times 2009$ & 91.17 & 17.58 & 0.000 & 56.71 to 125.62 \\
\hline Emo $\times 2010$ & 85.04 & 17.58 & 0.000 & 50.58 to 119.5 \\
\hline Emo $\times 2011$ & 86.53 & 17.58 & 0.000 & 52.07 to 121.00 \\
\hline Constant & 165.16 & 8.56 & 0.000 & 148.39 to 181.94 \\
\hline \multicolumn{5}{|c|}{$\begin{array}{l}\text { Anx = anxiety. Emo = emotional distress. SE = standard error. For example, an 18-year-old male with depression in } \\
2007 \text { is the reference: on average he had } 165 \text { illness days (constant). For females, } 5.69 \text { days should be added; for } \\
\text { each year's increase in age, } 0.2 \text { days should be added. For anxiety, } 103 \text { days should be subtracted. For the same } \\
\text { male with depression in } 2008,128 \text { days should be subtracted. Whereas for a male of } 18 \text { years with anxiety in } 2008 \text {, } \\
103 \text { days }+128 \text { days should be subtracted; however, the interaction effect means that } 88 \text { days should be added. The } \\
88 \text { days refers to the } 87.63 \text { coefficient in the group year } \times \text { year column. }\end{array}$} \\
\hline
\end{tabular}

Figure 1. Number of illness days due to index episode for depression, anxiety, and emotional distress.

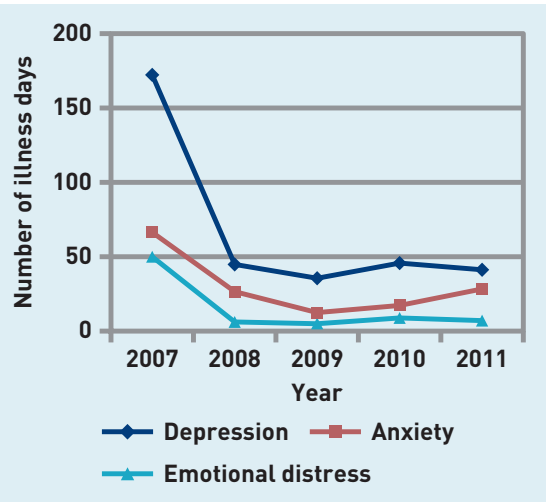

approximately two-thirds of the patients were female. In both respects there was no significant difference between groups. Of those included in the depression group, $77 \%$ had a depressive disorder and 23\% had depressive symptoms; and in the anxiety group, 33\% had an anxiety disorder and $67 \%$ had nervous symptoms. Those included in the emotional distress group had distress symptoms.

Descriptive statistics were used to describe the study population. Differences between groups were tested using the $\chi^{2}$ test. Trends in episode days, prescriptions, and contacts between 2007 and 2011 were analysed with multilevel analyses, with events nested within patients, and patients nested within practice. The model was adjusted for general practice, sex, and age.

Differences were considered significant when $P<0.05$. Stata (version 13.1) was used to analyse the data.

\section{RESULTS}

\section{Characteristics of the study sample}

The mean ages of patients in all groups and the control group were between 46.9 and 48.8 years (Table 1). In each group

\section{First and recurrent episodes}

The first episode of depression lasted significantly longer than an episode of anxiety or emotional distress $(P<0.001)$; the same applied to the length of the recurrent episodes $(P<0.001)$ (Table 1$)$.

The length of a recurrent index episode did not differ significantly from the length of the first index episode.

\section{Five-year course}

Patients in the depression group experienced more episodes of depression than patients in the other groups experienced their respective episodes (Table 1). Patients with depression had more days with depression 


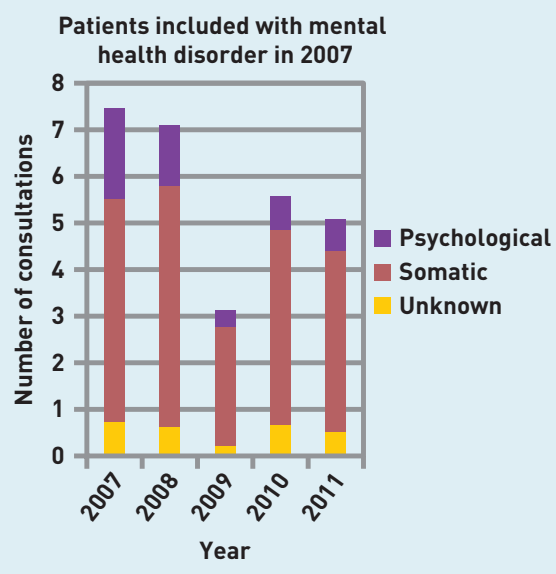

Figure 2. Number of consultations for psychological and somatic reasons in patient group (depression, anxiety, and emotional distress groups combined) and control group, 2007-2011.

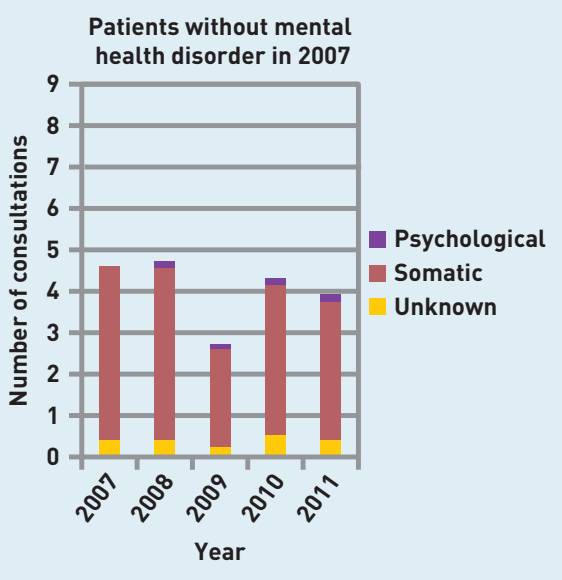

than patients in the other groups had anxiety days or distress days, respectively. After 5 years, more patients who were depressed in 2007 still had a diagnosis of depression

Table 3. Mean number of contacts (total, somatic, psychological), corrected for age, sex, and GP practice

\begin{tabular}{|c|c|c|c|c|c|c|}
\hline \multirow[b]{2}{*}{ Variable } & \multicolumn{2}{|c|}{$\begin{array}{c}\text { Total number of } \\
\text { consultations }\end{array}$} & \multicolumn{2}{|c|}{$\begin{array}{l}\text { Consultations for } \\
\text { psychological problem }\end{array}$} & \multicolumn{2}{|c|}{$\begin{array}{l}\text { Consultations for } \\
\text { somatic problem }\end{array}$} \\
\hline & Coefficient & SE & Coefficient & SE & Coefficient & SE \\
\hline Age & $0.08^{a}$ & 0.003 & 0.001 & 0.001 & $0.07^{a}$ & 0.003 \\
\hline Sex & $1.16^{\mathrm{a}}$ & 0.11 & 0.02 & 0.02 & $1.01^{a}$ & 0.10 \\
\hline \multicolumn{7}{|l|}{ Patient group } \\
\hline Control & $-3.23^{a}$ & 0.29 & $-2.20^{a}$ & 0.07 & $-0.79^{b}$ & 0.25 \\
\hline Depression (ref) & & & & & & \\
\hline Anxiety & -0.54 & 0.39 & $-0.52^{\mathrm{a}}$ & 0.09 & -0.21 & 0.33 \\
\hline Emotional distress & 0.23 & 0.51 & $-0.31^{b}$ & 0.12 & 0.19 & 0.44 \\
\hline \multicolumn{7}{|l|}{ Year } \\
\hline \multicolumn{7}{|l|}{2007 (ref) } \\
\hline 2008 & $-0.66^{b}$ & 0.33 & $-0.54^{a}$ & 0.08 & -0.02 & 0.28 \\
\hline 2009 & $-4.58^{a}$ & 0.33 & $-1.81^{a}$ & 0.08 & $-2.37 a$ & 0.28 \\
\hline 2010 & $-1.61^{a}$ & 0.33 & $-1.43^{a}$ & 0.08 & -0.28 & 0.28 \\
\hline 2011 & $-2.04^{a}$ & 0.33 & $-1.52^{\mathrm{a}}$ & 0.08 & -0.48 & 0.28 \\
\hline \multicolumn{7}{|l|}{ Group $\times$ year } \\
\hline Ctrl $\times 2008$ & $0.75^{b}$ & 0.34 & $0.70^{a}$ & 0.09 & -0.06 & 0.29 \\
\hline Ctrl $\times 2009$ & $2.67^{a}$ & 0.34 & $1.91^{\mathrm{a}}$ & 0.09 & 0.57 & 0.29 \\
\hline Ctrl $\times 2010$ & $1.34^{\mathrm{a}}$ & 0.34 & $1.64^{\mathrm{a}}$ & 0.09 & -0.32 & 0.29 \\
\hline Ctrl $\times 2011$ & $1.34^{\mathrm{a}}$ & 0.34 & $1.70^{\mathrm{a}}$ & 0.09 & -0.44 & 0.29 \\
\hline Anx $\times 2008$ & 0.48 & 0.46 & -0.03 & 0.12 & 0.51 & 0.39 \\
\hline Anx $\times 2009$ & 0.44 & 0.46 & $0.46^{\mathrm{a}}$ & 0.12 & 0.08 & 0.39 \\
\hline Anx $\times 2010$ & -0.61 & 0.46 & $0.36^{b}$ & 0.12 & $-0.85^{b}$ & 0.39 \\
\hline Anx $\times 2011$ & $-0.98^{b}$ & 0.46 & $0.32^{b}$ & 0.12 & $-1.13^{b}$ & 0.39 \\
\hline Emo $\times 2008$ & 0.41 & 0.61 & $-0.42^{b}$ & 0.15 & 0.62 & 0.51 \\
\hline Emo $\times 2009$ & 0.37 & 0.61 & -0.24 & 0.15 & -0.32 & 0.51 \\
\hline Emo $\times 2010$ & -0.20 & 0.61 & 0.47 & 0.15 & -0.13 & 0.51 \\
\hline Emo $\times 2011$ & 0.31 & 0.61 & $0.85^{\mathrm{a}}$ & 0.15 & -0.12 & 0.51 \\
\hline Constant & $7.13^{a}$ & 0.43 & $2.20^{a}$ & 0.07 & $4.34^{a}$ & 0.39 \\
\hline
\end{tabular}

${ }^{a} P<0.001 .{ }^{b} P<0.05$. Anx $=$ anxiety. Ctrl $=$ control. Emo = emotional distress. $S E=$ standard error. For example, total number of contacts for an 18-year-old male with depression in 2007 is the reference: on average he had 7.13 contacts (constant). For females, 1.16 contacts should be added; for each year's increase in age, 0.08 contacts should be added. For anxiety, 0.54 contacts should be subtracted. For the same male with depression in 2008, 0.66 contacts should be subtracted. Whereas for a male of 18 with anxiety in 2008, 0.54 contact +0.66 contacts should be subtracted; however, the interaction effect means that 0.48 contacts should be added.

in $2011(154 ; 34 \%)$, than did patients with anxiety (106; $24 \%$ ), or distress $(26 ; 14 \%)$.

Of the patients in the depression group, $28 \%$ had index episodes in all 5 years and $23 \%$ only in 2007 ; this holds for $21 \%$ and $29 \%$ of patients, respectively, in the anxiety group, and $6 \%$ and $50 \%$, respectively, of patients in the emotional distress group. Differences between the three patient groups during 5 years (controlling for age, sex, and practice) are tested in Table 2. The mean number of episode days/year in each group is presented in Figure 1.

Patients in the depression group had more illness days each year than those in the anxiety or distress group, and each year after 2007 had significantly fewer illness days than in 2008, but the year effect and the diagnosis effect interact. The interaction effect is illustrated in Figure 1: there is a much sharper decrease of depression days between 2007 and 2008 than of anxiety or distress days.

\section{Healthcare use}

The differences in healthcare use are presented in Figure 2 and tested in Table 3. Because of the small differences between the three patient groups in this respect, data for these groups have been combined in Figure 2.

In general there was a decrease in the number of consultations in 2009, due to the absence of some managed care data. The patients with any kind of mental health condition had significantly more consultations compared with those in the control group during all years $(P<0.001)$. During all followup years, the total number of contacts decreased significantly for patients in the mental health disorder groups $(P<0.001)$, whereas in the control group they remained more or less stable (Table 3).

However, even in 2011 the number of consultations for patients included with mental health disorders in 2007 exceeds the number for the control group by almost $40 \%$. The decrease in consultations in the mental health disorder groups is to be found mainly in the consultations for mental health conditions. Patients in the mental health disorder group also had significantly more contacts for somatic problems than patients in the control group during all years, but this difference was relatively small. The control group was relatively stable in terms of the number of consultations for mental health disorder or somatic problems.

\section{Pharmacotherapy}

Psychopharmacological treatment was prescribed frequently in the first year 


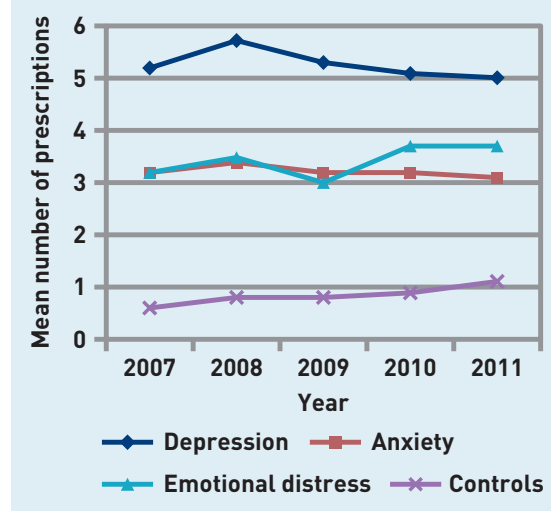

Figure 3. Mean number of prescriptions for psychopharmacological treatment for patients with depression, anxiety, and emotional distress, and control patients, 2007-2011.
(Figure 3). The level of prescriptions hardly decreased during the 5 years of the followup. All groups received significantly more psychopharmacological treatment than the control group for all years $(P<0.001)$. In 2011,317 (70\%) of patients in the depression group, $265(60 \%)$ in the anxiety group and $89(48 \%)$ in the emotional distress group were still receiving some kind of psychopharmacological medication. This was also the case for $24 \%$ in the control group in 2011

\section{DISCUSSION}

\section{Summary}

The results showed that, after the first index episode, patients with depression had on average 1.1 more episodes of depression, patients with anxiety had 0.9 recurrent episodes of anxiety, and patients with emotional distress had 0.5 further emotional distress episodes during the 5 follow-up years (Table 1).

The total number of GP contacts was more for patients in the depression, anxiety, and emotional distress groups than those in the control group, for both psychological and non-psychological reasons, during all 5 years of follow-up. Compared with the control group, the patients with depression, anxiety, or emotional distress received more prescriptions for psychopharmacological treatment during all follow-up years.

Patients in the depression group were more often diagnosed with a mental health disorder (P76, depressive disorder), whereas patients in the anxiety and distress groups were more frequently diagnosed with mental symptoms ( $\mathrm{P} 01$, feeling anxious, nervous; P02, stress). Patients included with symptoms have a better prognosis in several respects: shorter episodes, fewer recurrent episodes, fewer days with symptoms, and less chronicity.

\section{Strengths and limitations}

This study is representative of the Dutch population. The results could also be generalised to countries with a similar primary care system where the GP fulfils a gatekeeper role.

This study had several strengths. First, the research had a follow-up time of 5 years after the index episode; second, a large study population was included. The third strength is that all index episode dates were manually verified for all patients. Fourth, the analysis was restricted to patients in primary care whose index episode was identified by the GP. However, bias due to selection of GPs may have influenced the results in a positive way, because the GPs registering for NIVEL have to observe strict guidelines regarding complete registration of their data.

The results should be interpreted with the following limitations in mind. The study relied on the classifications made by GPS during their routine consultations. GPs within the network (NIVEL Primary Care Database) are screened for completeness of data; they get yearly feedback that may help improve the quality of registration.

The smaller number of contacts in 2009 is a drawback in the original data that could be explained by the introduction of 'managed care' for some chronic diseases such as diabetes. Data about diabetes care were recorded in a separate register.

Second, the first episode listed for the included patients only implies that there was no index disorder episode during the previous 3 months. It is possible that patients have a lengthy history of the index disorder before this time. The same arbitrary decision has been made about the end of an episode: if no new prescriptions, referrals, or contacts occur that are related to an episode for 3 months, it is counted as 'ended'. There may have been inter-GP bias with difference in sensitivity between different GPs for psychological problems. This limitation was resolved by adjusting for the general practice concerned with multilevel analysis.

Last, there are no good indicators about the severity of the mental health disorders available: the registering doctors were not assessing severity in any way. However, the severity of common mental health disorders are major predictors for helpseeking, treatment, or outcomes. ${ }^{9.18,28}$

\section{Comparison with existing literature}

In this study, 258 (57\%) of patients with depression had a recurrent episode. Van Weel-Baumgarten et al ${ }^{24}$ reported approximately 30\% recurrence after 5 years. Systematic reviews have reported $30-65 \%$ recurrence of depressive illness in general practice..$^{21,25}$ Lloyd et a ${ }^{26}$ reported recurrent psychiatric episodes among onethird of patients presenting with a neurotic disorder'. The percentage of patients with recurrences in the current study is on the high side compared with earlier studies. It may have been lower if a new episode had been defined as occurring after an interval of longer than 3 months. The current study found an average length of 170 days for the first episode of depression. Van Weel-Baumgarten et al ${ }^{24}$ reported a mean duration of 103 days for the first episode. The mean episode length of a first 
episode of emotional distress is shorter which is in line with existing literature. ${ }^{3}$ According to this, patients with symptoms and syndromes that are not defined as clear-cut psychiatric conditions have a better prognosis than a defined clear-cut psychiatric condition such as depression, which corresponds to the current study results.

Psychiatric epidemiological studies report $80 \%$ of patients with depression and $46 \%$ of patients with anxiety achieve remission within 2 years. ${ }^{18}$ Although it may be concluded that a significant proportion of the symptoms have disappeared, patients nevertheless keep presenting some symptoms at GP visits and stick to their psychopharmacological therapy. The high prescription rates found for the first episode for all patient groups is consistent with previous studies. 4,8,9,30 The higher number of contacts for psychological and somatic reasons for patients with depression, anxiety, or emotional distress are also found in other studies. ${ }^{11-15}$

\section{Implications for practice}

The data demonstrate that patients with depression develop a kind of help-seeking behaviour, with a recurring psychological need for help, combined with an increased need for help with physical symptoms. ${ }^{31}$ Patients with anxiety and distress, mostly at symptom level, show a similar pattern but to a lesser degree. Johnston et ${ }^{{ }^{32}}{ }^{2}$ argued that depression is better treated within a chronic care model loffering regular opportunities for counselling) instead of a disease model, implying a 'cure'. Thinking in terms of a chronic care model, perhaps some of the results from the current study that are presented as indicators for a poor prognosis could be reconsidered. It may be the case that some patients are treated appropriately with long-term antidepressant use. Such treatment may keep these patients symptom-free. Nevertheless, they are considered in this study as still experiencing an episode of depression, as defined by their long-term use of antidepressants and the resulting periodic consultations about their depression. However, their continuing significant use of medical services for all kinds of symptoms, compared with average patients, indicates chronic suffering.

Implementing a chronic care model requires substantial adaptations in daily practice regarding decision support, delivery system design, and clinical information systems. ${ }^{33}$ When collaborative care models with depression were successfully implemented, depression symptoms improved, as did adherence to treatment, response to treatment, and quality of life/ functional status. This was reported in a 2012 meta-analysis. ${ }^{34}$

Such an implementation may be more feasible in Dutch general practice than in other countries because most Dutch GP practices are supported by mental health nurses, who can act as case managers. For instance, a practice nurse, acting as a case manager, may monitor patients with long-term depression, provide some short-term interventions if necessary, arrange medication reviews if deemed necessary, and support patients who may try to suddenly stop long-term use of antidepressants.

\section{Ethical approval}

The study was based on secondary data from NIVEL Primary Care Database with patients' consent. The participating GPs briefed the patients by leaflets and posters, and it was always possible for them to refuse registration. NIVEL did not receive information through which it was possible to identify patients. According to Dutch legislation, neither obtaining informed consent nor approval by a medical ethics committee was obligated for database studies without direct patient involvement.

\section{Provenance}

Freely submitted; externally peer reviewed.

\section{Competing interests}

The authors have declared no competing interests.

\section{Discuss this article}

Contribute and read comments about this article: bjgp.org/letters 


\section{REFERENCES}

1. de Graaf R, ten Have M, van Gool C, van Dorsselaer S. Prevalence of mental disorders and trends from 1996 to 2009. Results from the Netherlands Mental Health Survey and Incidence Study-2. Soc Psychiatry Psychiatr Epidemiol 2012; 47(2): 203-213.

2. Rosendal M, Vedsted P, Christensen KS, Moth G. Psychological and social problems in primary care patients: general practitioners' assessment and classification. Scand J Prim Health Care 2013; 31(1): 43-49.

3. Terluin B, Winnubst JA, Gill K. [Characteristics of patients with the diagnosis 'mental strain' in family practice]. [Dutch]. Ned Tijdschr Geneesk 1995; 139(35): 1785-1789

4. Verhaak PF, van Dijk CE, Nuijen J, et al. Mental health care as delivered by Dutch general practitioners between 2004 and 2008. Scand J Prim Health Care 2012; 30(3): 156-162.

5. Janssen EH, van de Ven PM, Terluin B, et al. Recognition of anxiety disorders by family physicians after rigorous medical record case extraction: results of the Netherlands Study of Depression and Anxiety. Gen Hosp Psychiatry 2012 34(5): 460-467.

6. Piek E, Nolen WA, van der Meer K, et al. Determinants of (non-Jrecognition of depression by general practitioners: results of the Netherlands Study of Depression and Anxiety. J Affect Disord 2012; 138(3): 397-404

7. Saltini A, Mazzi MA, Del Piccolo L, Zimmermann C. Decisional strategies for the attribution of emotional distress in primary care. Psychol Med 2004; 34(4): 729-739

8. van Rijswijk E. Mental health problems in general practice: an explorative study on diagnosis and treatment. Thesis: Nijmegen: Radboud University, 2005

9. Bushnell J, McLeod D, Dowell A, et al. The treatment of common mental health problems in general practice. Fam Pract 2006; 23(1): 53-59.

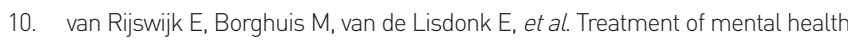
problems in general practice: a survey of psychotropics prescribed and other treatments provided. Int J Clin Pharmacol Ther 2007; 45(1): 23-29.

11. van Weel-Baumgarten EM, van den Bosch WJ, van den Hoogen HJ, Zitman FG. The long-term perspective: a study of psychopathology and health status of patients with a history of depression more than 15 years after the first episode. Gen Hosp Psychiatry 2000; 22(6): 399-404.

12. Lamers F, van Oppen P. Comijs HC, et al. Comorbidity patterns of anxiety and depressive disorders in a large cohort study: the Netherlands Study of Depression and Anxiety (NESDA). J Clin Psychiatry 2011; 72(3): 341-348.

13. Gili M, Comas A, Garcia-Garcia M, et al. Comorbidity between common mental disorders and chronic somatic diseases in primary care patients. Gen Hosp Psychiatry 2010; 32(3): 240-245

14. Penninx BW, van Dyck R. [Depression and somatic comorbidity]. [Dutch]. Ned Tijdschr Geneeskd 2010; 154: A1784.

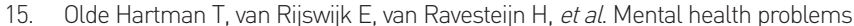
and the presentation of minor illnesses: data from a 30-year follow-up in general practice. Eur J Gen Pract 2008; 14(Suppl 1): 38-43.

16. Hughes S, Cohen D. A systematic review of long-term studies of drug treated and non-drug treated depression. J Affect Disord 2009; 118(1-3): 9-18.

17. Ormel J, Koeter MW, van den Brink W, van de Willige G. Recognition, management and course of anxiety and depression in general practice. Arch Gen Psychiatry 1991; 48(8): 700-706.

18. Penninx BW, Nolen WA, Lamers F, et al. Two-year course of depressive and anxiety disorders: results from the Netherlands Study of Depression and Anxiety (NESDA). J Affect Disord 2011; 133(1-2): 76-85

19. Poutanen O, Mattila A, Seppälä NH, et al. Seven-year outcome of depression in primary and psychiatric outpatient care: results of the TADEP (Tampere Depression) II Study. Nord J Psychiatry 2007; 61(1): 62-70.

20. Stegenga BT, Kamphuis MH, King M, et al. The natural course and outcome of major depressive disorder in primary care: the PREDICT-NL study. Soc Psychiatry Psychiatr Epidemiol 2012; 47(1): 87-95.

21. Steinert C, Hofmann M, Kruse J, Leichsenring F. The prospective longterm course of adult depression in general practice and the community. A systematic literature review. J Affect Disord 2014; 152-154: 65-75.

22. Yiend J, Paykel E, Merritt R, et al. Long term outcome of primary care depression. J Affect Disord 2009; 118(1-3): 79-86.

23. Culpepper L. Generalized anxiety disorder in primary care: emerging issues in management and treatment. J Clin Psychiatry 2002; 63(Suppl 8): 35-42.

24. van Weel-Baumgarten E, van den Bosch W, van den Hoogen H, Zitman FG. Ten year follow-up of depression after diagnosis in general practice. Br J Gen Pract 1998; 48(435): 1643-1646.

25. van Weel-Baumgarten EM, Schers HJ, van den Bosch WJ, et al. Long-term follow-up of depression among patients in the community and in family care settings. A systematic review. J Fam Pract 2000; 49(12): 1113-1120.

26. Lloyd KR, Jenkins R, Mann A. Long-term outcome of patients with neurotic illness in general practice. BMJ 1996; 313(7048): 26-28.

27. McCracken C, Dalgard OS, Ayuso-Mateos JL, et al. Health service use by adults with depression: community survey in five European countries. Evidence from the ODIN study. Br J Psychiatry 2006; 189: 161-167.

28. Codony M, Alonso J, Almansa J, et al. Perceived need for mental health care and service use among adults in Western Europe: results of the ESEMeD project. Psychiatr Serv2009; 60(8): 1051-1058

29. Lamberts $\mathrm{H}$, Wood M. International classification of primary care. Oxford: Oxford University Press, 1987.

30. Spies T, Mokkink H, de Vries Robbé P, Grol R. Huisarts kiest vaak voor antidepressiva onafhankelijk van de ernst van de depressie. [GP prescribes antidepressants irrespective of severity of depression]. [Dutch]. Huisarts We 2004; 47(8): 419-423

31. Tylee A, Walters P. We need a chronic disease management model for depression in primary care. Br J Gen Pract 2007; 57(538): 348-350.

32. Johnston O, Kumar S, Kendall K, et al. Qualitative study of depression management in primary care: GP and patient goals, and the value of listening. Br J Gen Pract 2007; 57(544): 872-879

33. Kilbourne AM, Schulberg HC, Post EP, et al. Translating evidence-based depression management services to community-based primary care practices. Milbank Q2004; 82(4): 631-659.

34. Thota AB, Sipe TA, Byard GJ, et al. Collaborative care to improve the management of depressive disorders: a community guide systematic review and meta-analysis. Am J Prev Med 2012; 42(5): 525-538. 